\title{
Longitudinal study of the results of continuous improvement in an industrial company.
}

\author{
Juan A. Marin-Garcia \\ Universidad Politécnica de Valencia. \\ Manuela Pardo del Val \\ Universidad de Valencia. \\ Tomás Bonavía Martín \\ Universidad de Valencia.
}

$\mathrm{Ph}$. D. Juan Marin is lecturer at the Department of Business Administration in the Polytechnic University of Valencia (Spain). He lectures on management, teamwork and management information systems. With regard to these areas he has also worked as a consultant for some companies in Spain and El Salvador (Central America). His main research fields are: participative management, lean manufacturing systems, performance evaluation and active learning in higher education

Ph. D.Manuela Pardo del Val works at the Faculty of Economy in the University of Valencia (Spain) for ten years. She lectures topics dealing with strategic management and human resources. Regarding research background, her $\mathrm{PhD}$, entitled "Participative management as invigorating element in organizational change" was awarded with Excellent Cum Laude within European recognition. Her main research lines are management, organizational change, and tourism. Articles regarding these topics have been published in the Leadership and Organization Development Journal, Management Studies, and International Journal of Quality and Reliability Management, among others.

Ph. D.Tomas Bonavia is lecturer at the Department of Social Psychology in the University of Valencia (Spain). He has published articles in the areas of work and organizational psychology, and economic and consumer psychology. His main research topic is about participative management. He has participated in numerous international congresses on these subjects.

Send correspondence to:

Juan A. Marin-Garcia

Universidad Politécnica de Valencia - Edificio 7D

Dept. Organización de Empresas

App. Correos: 22012

46071- Valencia-SPAIN

Tel: 963877007 Ext. 76853

Fax: 963877689

Correo Electrónico: jamarin@omp.upv.es

\section{Acknowledgements:}

We would like to thank the $R+D+i$ Linguistic Assistance Office at the Universidad Politecnica of Valencia for their help in translating this paper. 


\section{Longitudinal study of the results of continuous improvement in an industrial company.}

\section{$\underline{\text { Research paper. }}$}

Purpose: Some of the most widely-used tools for continuous improvement are the individual or group suggestion systems. In this paper we summarize the main characteristics of both systems and how to implement them. The purpose of this paper is to ask the following research questions: What are the outcomes of individual or group suggestion systems implementation? Which of the two programs, individual or groups, is more profitable for the companies? What problems arise during the use of these programs?

Methodology: Case Study, we will analyse the evolution of the formal programs of continuous improvement of a firm in a traditional sector (food) over the course of 5 years. The data for our research were gathered by means of participatory observation over the course of 18 months spent in the firm attending the meetings of the improvement teams.

Findings: Both programs (individual and group) have proved to be very profitable for the company. However, we have seen that there is no magic formula for the correct operation of the system of continuous improvement, but that the existing system has to be continually improved, correcting faults and trying always to contribute something new to re-launch the system every so often.

Practical implication: This study has also permitted us to highlight the importance of continuous improvement in the firm from both the economic point of view and that of worker development.

Value of paper: Our investigation aims to help to cover the lack of longitudinal case studies of continuous improvement. Our data show a real experience of how a scheme of continuous improvement has been gradually transformed, from a very unsuccessful start, passing through different phases and finally delivering results for the firm. 
Keywords: continuous improvement, suggestions systems, improvement team, performance, cost reduction

\section{INTRODUCTION:}

The current environment in which many industrial firms operate is characterised by intense competition (Bond 1999), with an increasingly predominant role of new technologies (Garcia-Lorenzo \& Prado 2003). In this context, continuous improvement is a weapon for maintaining and improving competitiveness, making use of the knowledge and the involvement of the firm's workers (Garcia-Lorenzo \& Prado 2003;Prado Prado 1998;Terziovski \& Sohal 2000;van Dijk \& van den Ende 2002;Wood 2003). Although continuous improvement may be originated by the ideas or proposals of managers, technicians or consultants, it can also be encouraged by the creativity and involvement of the workers (Bodek 2002;Fairbank \& Williams 2001;Garcia-Lorenzo \& Prado 2003;Grütter et al. 2002; Kerrin \& Oliver 2002;Lloyd 1999;Prado 2001). In this sense, suggestions systems and improvement teams are some of the tools that enable continuous improvement to be set in motion utilising workers' ideas.

Many authors have considered continuous improvement as one of the basic tools for implanting systems of production based on total quality management, Lean Production or World Class Manufacturing (Bacdayan 2001;Bond 1999;Frese et al. 1999;Grütter et al. 2002;Jackson \& Dyer 1998;Schonberger 1996;Tapping et al. 2002). However, continuous improvement can be used as a tool for the functioning of any organisation, even if it is not based on these advanced methodologies (Rapp \& Eklund 2002). We should not forget the importance to the firm of implementing small improvements of a cumulative character, which in the end produce important and lasting results (Bond 1999;Choi et al. 1997;Fairbank \& Williams 2001). It is surprising that there are not many scientific publications that deal with these improvement tools, despite the fact 
that they form the basis of many methodologies on which much more has been published (Frese et al. 1999).

Among firms' principal motives for implementing continuous improvement, we can highlight the improvement of productivity or efficiency (Grütter et al. 2002;Rapp \& Eklund 2002), quality (Grütter et al. 2002), the reduction of production costs (Bond 1999;Modarress et al. 2005;Terziovski \& Sohal 2000) or of time of manufacture (Grütter et al. 2002). We must take into account that these benefits are not always achieved immediately and some time must pass before the incremental improvements take effect (Rapp \& Eklund 2002). However there are very few empirical studies that analyse the long term impact of continuous improvement (Grütter et al. 2002). It is therefore necessary to undertake studies to evaluate the results achieved in long implementations.

Our study aims to help to cover the lack of longitudinal case studies of continuous improvement (Grütter et al. 2002). In it we will identify phases that the continuous improvement program goes through in a firm, the results obtained and the differences in the implantation of the systems of suggestions and of improvement teams. Furthermore, our analysis is carried out in a Spanish firm in the food industry, of medium size, mature, family-owned and with traditional systems of manufacture. That is to say, in a context very little explored in the scientific publications that focus on the application of continuous improvement in firms.

\section{CONTINUOUS IMPROVEMENT}

Continuous improvement can be defined as small incremental changes in productive processes or in working practices that permit an improvement in some indicator of performance (Grütter et al. 2002), that do not require big investments in order to implement them, and in which all members of the firm are involved (Terziovski \& Sohal 
2000). The themes most frequently analysed are the improvement of the quality or costs of manufacture, though matters of health and safety at work are also common (Albors \& Hervás 2006;Bañegil 1993;Terziovski \& Sohal 2000).

Continuous improvement is based on the Deming cycle, consisting of four phases: studying the current situation, gathering the data necessary to propose the suggestions for improvement; setting in motion trials of the proposals selected; checking whether the proposal tested is giving the expected results; implementation and standardising the proposal with the necessary modifications (Bond 1999;Terziovski \& Sohal 2000)

There are various ways of implementing continuous improvement in the firm. The best results are obtained when the improvement originates from a group, either through permanent groups such as quality circles (García Lorenzo \& Prado Prado 2001;Grütter et al. 2002;Kerrin \& Oliver 2002;Rapp \& Eklund 2002; Sillince et al. 1996) or through multifunctional or self-regulating work teams that incorporate the continuous improvement activities among their responsibilities (Kerrin \& Oliver 2002;Rapp \& Eklund 2002); or through improvement teams of predetermined duration (García Lorenzo \& Prado Prado 2001;Grütter et al. 2002;Kerrin \& Oliver 2002;Rapp \& Eklund 2002).

Individual suggestions systems can also be implemented (Prado 2001;Rapp \& Eklund 2002;Schuring \& Luijten 2001; Sillince et al. 1996), though they only obtain results comparable to groups if they are exceptionally well managed (Rapp \& Eklund 2002).

In our study we will focus on programs that add a parallel structure to which workers dedicate only a part of their time (de Lange-Ros \& Boer 2001; Sillince et al. 1996;Stohl 1987). In this sense, we can consider that the programs that first appeared in firms were suggestions systems, followed by quality circles and, later, improvement teams were introduced (Garcia-Lorenzo \& Prado 2003). In a recent study of Spanish firms with more than 25 workers, the degree of use of these systems clearly inclines towards 
improvement teams (present in $74 \%$ of firms) and suggestions systems (present in $64 \%$ of firms), whereas quality circles are becoming less common (30\% of firms) (Garcia-Lorenzo \& Prado 2003). We believe this situation is not exclusive to Spain and the maintenance of the popularity of suggestions systems alongside the progressive substitution of quality circles by improvement teams can also be seen in Australia (Terziovski \& Sohal 2000) or in the United States (Lawler III et al. 2001).

We will now describe in more detail these two more popular types of programs for continuous improvement.

Individual suggestions systems offer a procedure for collecting and evaluating ideas provided by the firm's employees (van Dijk \& van den Ende 2002). They also allow the procedure for rewarding the workers for their ideas to be formalised (van Dijk \& van den Ende 2002). Normally, the workers make their suggestions through a suggestions box (Schuring \& Luijten 2001), filling in a paper or electronic form. Traditionally, once the worker has presented the idea, he or she has no further connection with the process and the responsibility passes to a committee that selects the winning ideas, the amount of the prize, and the persons or groups that will be charged with implementing the ideas approved (Frese et al. 1999;Lloyd 1999;Schuring \& Luijten 2001).

Improvement teams, moreover, share several characteristics with quality circles: they are formed by a small group of workers who meet periodically to identify, analyse and propose alternative solutions to problems related to their area of work. These groups only have autonomy to propose ideas, which are then evaluated by a committee of managers who decide which ideas should be implemented. Normally the people in the group take charge of the implementation of the ideas. The meetings are usually scheduled in working hours and no direct rewards are offered for belonging to these groups. Nevertheless, the ideas are usually rewarded depending on their utility to the firm. These prizes are awarded to the group for it to decide how to distribute them 
or spend them (Barrick \& Alexander 1987;Buch \& Spangler 1990;Greenbaum et al. 1988;Griffin 1988;Kerrin \& Oliver 2002; Lawler III 1991;Li-Ping et al. 1988;Rapp \& Eklund 2002; Sillince et al. 1996). However, improvement teams differ in that the members may not participate voluntarily, but be chosen by the management, and they usually belong to different areas of work or levels of the hierarchy. This composition propitiates complementary points of view and the discussion of problems that affect different areas. Furthermore, they are not usually structures as stable as quality circles as regards their duration and the membership of the team (Garcia-Lorenzo \& Prado 2003;Lawler III et al. 2001;Prado Prado 1998).

\section{INDICATORS OF RESULTS}

The degree of success of the implantation of continuous improvement programs has been studied from very different perspectives. Many studies are based on subjective perceptions, either by supervisors or by workers, of the advantages deriving from the use of these programs. Some examples of this type are Sillince et al. ( 1996) or Terziowski and Sohal ( 2000). Others, however, use more objective indicators to measure the results, as for example Schroeder et al. (2002). As well as in the manner of measuring the success of the program, there is also a great variation in what is measured. To make a more detailed analysis of these aspects would distract us from the aim of this study, and has moreover been done in a recent paper (Nair 2006), which offers abundant bibliographies in this respect.

There exists a set of studies that analyse the success of the program in terms of the number of ideas generated or implemented and the number of workers involved (Frese et al. 1999;Griffin 1988;Rapp \& Eklund 2002;Schuring \& Luijten 2001;Sillince et al. 1996;Terziovski \& Sohal 2000;van Dijk \& van den Ende 2002). Our study will use similar indicators. 
With respect to the evolution of the performance of the improvement programs, there seems to be a consensus that the life cycle of these programs usually lasts between 24 and 48 months. In this cycle we can identify three phases: the initial introduction period, in which participation is limited to a few pilot experiments; diffusion of the experience in the firm; decline (some authors identify this as the "honeymoon effect"), generated by many factors including the resistance of middle managers, the failure of implementation of some of the ideas approved, few ideas proposed because it becomes more and more difficult to find points to improve, or increase in the cost of maintaining the program (Barrick \& Alexander 1987; Lawler III 1991; Sillince et al. 1996;Stohl \& Coombs 1988). In some cases there is a fourth phase, the relaunching of the program (Rapp \& Eklund 2002)

\section{FACILITATORS OF THE PROGRAMS}

The list of factors that favour success is common to all the different programs of continuous improvement and has been summarised in Table I.

(Please, insert table I here)

One of the first aspects is the active involvement of workers making suggestions and the involvement of managers, for example in the committees of supervision of the suggestions. Another way to demonstrate the involvement of management is by designating a "continuous improvement leader" whose task it is to coordinate all the actions.

Another important aspect is that the firm commits itself by providing training for the participants in continuous improvement programs, showing them the techniques that they need to be able to solve the more complex problems and to keep up people's 
interest in the program. It is also necessary for the program to be maintained for a sufficient time so that its results can be appreciated. In the case of group systems, the group should meet frequently.

It also helps to underline the importance of receiving a large number of suggestions, and that the proposals should focus on changes that are simple, cheap and easy to implement, as there is always time, money and personnel available to set small changes in motion. And it should not be forgotten that the degree of implementation of the suggestions made will affect the motivation to present future proposals.

The process of evaluation of the ideas must be carried out in a short time, and the authors of the proposals must be kept informed. Likewise, the process of implementing the ideas must be rapid and the workers who propose the ideas should participate in it, so it is recommendable that the suggestions for improvement should focus on their own area of work.

Economic incentives can provide motivation for participating in the program, especially if, as in some firms, good ideas are rewarded even if they are not implemented. Deciding the amount of the rewards is not easy (Kerrin \& Oliver 2002). It may be related to the benefits the idea brings to the firm, though the reward should not be directly proportional to the savings made, to avoid workers focussing on the search for one magnificent idea that will generate a big saving instead of presenting a large quantity of ideas, which is what keeps the system alive (Bodek 2002; Lloyd 1999;Schuring \& Luijten 2001). Some firms consider that if the suggestion has been devised in working hours, those hours are already paid by the firm and therefore no additional remuneration should be added. This is the reason why some firms reward only individual suggestions and not those made by groups that meet during working hours (Kerrin \& Oliver 2002). 


\section{RESEARCH QUESTION AND METHODOLOGY}

In our research we aim to find answers to the following questions:

1. What phases does the continuous improvement program go through in the firm?

2. What results are obtained with the systems of suggestions and of improvement teams?

3. What differences are there in the implementation of one program or the other? What factors of success have been activated? How?

To answer them we will analyse the evolution of the formal programs of continuous improvement of a firm in a traditional sector (food) over the course of 5 years. The firm is Spanish, mature, of small size (though close to medium size), family-owned, and its production philosophy is mass production. All these variables have been highlighted as factors conditioning the degree of application of continuous improvement systems (Albors \& Hervás 2006;Fabi \& Pons 1995;Grütter et al. 2002;Sanchez et al. 1999; Sillince et al. 1996;Terziovski \& Sohal 2000)

Our investigation aims to help to cover the lack of longitudinal case studies of continuous improvement (Grütter et al. 2002). To date, we have not found scientific publications that focus on the application of continuous improvement in Spanish firms in the food industry and of the size of "our" firm. Also unusual are publications on mature, family-owned firms with traditional systems of manufacture (which are the majority in Spain).

The data for our research were gathered by means of participatory observation over the course of 18 months spent in the firm attending the meetings of the improvement teams. We have followed the methodological recommendations of Yin ( 1994) and Lange-Ros and Boer ( 2001). The data of the study are taken from the firm's archives; 
from the notes taken at the meetings of the teams and during the evaluation of the proposals; from interviews with the managers and with the firm's continuous improvement leader; and from informal conversations with the members of the improvement teams.

In our study, the indicators of results of the continuous improvement programs will be:

- Number of ideas per employee and year (Rapp \& Eklund 2002;Schuring \& Luijten 2001)

- Degree of implementation of ideas: percentage of ideas implemented out of those received (Rapp \& Eklund 2002;Terziovski \& Sohal 2000;van Dijk \& van den Ende 2002)

- Savings generated by the ideas implemented (in euros) (van Dijk \& van den Ende 2002)

\section{CASE STUDY}

\section{DESCRIPTION OF THE FIRM}

The firm FOODSA ${ }^{1}$, is dedicated to the preparation and commercialisation of pork and turkey meat products. It is situated among the largest $10 \%$ of firms and with best financial results in its industry and has received the recognition of several public institutions. Currently, the firm is run by the third generation of the family. We can consider it a "traditional" organisation with a bureaucratic culture, using rules, policies, hierarchical authority, written documentation and systems of rewards to influence the behaviour of its employees and value its performance. However, for some years a change has been occurring in which it is being attempted to orientate the

\footnotetext{
1 The name is fictitious, to guarantee anonymity
} 
entrepreneurial culture towards encouraging the involvement of workers in the making of decisions relating to their task or area of work and to the continuous improvement of the firm, propitiating a more dynamic and flexible environment.

\section{PROCESS OF MANUFACTURE}

The products are manufactured against inventory. For this purpose the firm takes into account the historical data, the forecasts of sales for the last month, and the trend of sales of the products. As these are perishable products, the safety stock has to be monitored so that it does not exceed twelve days. It is reviewed every week depending on what has been manufactured, and updated periodically.

In the production process the following sections can be distinguished: reception of goods, pre-manufacture processes (de-frosting, preparation, mincing, injection, kneading), sausage making, heat treatment, specific processes (de-moulding and slicing), packing, storage and dispatch.

The distribution of the plant is U-shaped. The product enters by the same area as where it is dispatched. This form of locating the working areas permits greater flexibility to adapt to changes in demand, increasing or decreasing the number of workers on a line and the number of tasks each one of them does.

The number of items is close to 200 , grouped into three families: cooked products, cured products and fresh products.

\section{THE FIRM'S PROGRAM OF CONTINUOUS IMPROVEMENT}

The program of continuous improvement in FOODSA began in January 2000, at the initiative of the management, and this initial program laid the basis for the current program of continuous improvement.

At the beginning the suggestions were placed in a box that was within sight of everybody, and they were collected every week. This method did not encourage the 
employees to participate, so the proposals were then handed in to the department of human resources.

The proposals must focus on improvements that do not touch on Union matters (wages, categories, working time, collective bargaining...) or those that are the direct responsibility of the firm's management (public relations, advertising, rights and obligations of the firm..). Nor can they propose studies or procedures that are already in progress in the firm's areas of activity, nor suggestions that involve changes in sources of supply.

Currently, improvements can be proposed either by individual employees or by groups of employees. The managers and technicians of the firm are excluded from the suggestions system or the improvement teams rewards.

\section{THE EXPERIENCE OF THE SUGGESTIONS SYSTEM}

The first year of existence of the suggestions program, no record was kept of the proposals, of which there were very few. From 2001 onwards some data are available. From 2004, the start of our study, a more detailed and systematic record was kept of the ideas proposed and their viability.

\section{Process of presentation of proposals.}

To present an idea or suggestion, a standardised form must be filled in. The presentation of suggestions may vary slightly in format so that the idea is clearly defined, but must reflect the basic requirements for presentation: the name of the author or authors, the date of the proposal, the problem or potential improvement detected, the type of solution proposed (improvement in quality, improvement of productive process, improvement of administrative process, logistical), the solution proposed, diagram of the solution, if necessary, and signature of the authors. 
Once the form has been completed, it should be handed in to the department of human resources, which, depending on the purpose of the idea, will send it to the corresponding department for study. The department in question evaluates in the shortest time possible its viability, effectiveness, cost, improvements introduced, savings made, disadvantages...and makes a report on the proposal. The evaluation report is sent to the department of human resources which transmits it to the person or group who has formulated the proposal. On many occasions, the ideas remained stagnated in the departments, and the evaluation did not take place or was not rigorous. For this reason in 2004 the procedure was changed, and the proposals were assessed by a person tasked with energising the system of continuous improvement .

If proposals are presented that are not viable at the time of their evaluation, but could be within a year of their presentation, the proposal is left in abeyance until the appropriate conditions for setting it in motion occurred.

The ideas implemented are published in the firm's monthly information sheet.

\section{Rewards for the contribution of ideas to the suggestions program.}

The ideas approved receive an economic gratification which depends on the saving calculated in the report on the proposal. Ideas that save less than $3,000 € /$ year are awarded a prize of $6 \%$ of the saving, with a limit of $150 €$. If the saving is between 3,000 and $30,000 € /$ year they receive $5 \%$, i.e. a gratification of between $150 €$ and $1,200 €$. Savings between 30,000 and $60,000 € /$ year receive $4 \%(1,200 €$ to $2,100 €)$. Savings greater than $60,000 € /$ year receive $3.5 \%$, with a limit of $6,000 €$ on the prize.

Furthermore, in the event that an idea does not produce a saving because its implementation requires an investment greater than the profits generated, but the management of the firm considers it appropriate to implement it for some reason 
(safety, tidiness, cleanliness, etc.) the authors of the idea are awarded a symbolic gratification of $60 €$.

The authors of ideas that are not considered suitable (for technical or economic reasons) enter into a draw for a parcel of products. The purpose of this draw is to thank the people in the firm for their effort and their contribution to continuous improvement.

The intellectual property of the ideas implemented and rewarded passes to the firm FOODSA.

\section{Results of the suggestions system}

In Table II we show the principal indicators of the results of the system. In it we can appreciate that the number of ideas presented is very variable. After 24 months the number of proposals, and the degree of implementation, declined. During 2003 an effort was made by the production managers to enhance the suggestions system. The result was a spectacular increase in the number of proposals presented, though many of them were not accepted. During 2004 the commitment of the management to the continuous improvement program increased and a manager was hired full time to act as "continuous improvement leader". This manager was hired because the accumulation of unassessed proposals was on the point of causing the death of the suggestions program. As well as systematising the calculation of the savings and the evaluation of the ideas, the continuous improvement leader was tasked with launching a pilot experiment with two improvement teams that ran parallel to the suggestions system and which we will detail in the next section.

We consider it worth noting that in the year 2005 the presentation of suggestions returned to the levels of 2001 , but the rate of acceptance of the proposals is very high (78\%) allowing an annual saving similar to that of the previous year. For the first three years no data are available on the calculation of savings, as they were done by 
different people, belonging to several departments, who did not always use the same criteria. Nor were copies kept of the assessment reports.

(Please insert table II approximately here)

Until 2004, in the suggestions system there was no monitoring of the savings achieved by the system. The calculation and subsequent divulging of the savings produced by the suggestions system in 2004 generated in the workers a change of attitude towards the suggestions program. The workers perceive that the ideas that they put forward are not forgotten about. They also feel involved in the changes and decisions that affect the firm, and feel satisfaction as a result.

Problems have appeared when attempting to quantify the savings from proposals relating to cleanliness, tidiness, ergonomics, etc. To solve them it is proposed to give a symbolic prize (between 12 and $30 €$ ) for these proposals. The amount will be determined by the human resources department in view of the creativity of the proposal.

Although the managers consider that the suggestions system is producing good results, some undesired effects occur. For example, sometimes the repair of a breakdown is presented as a proposal in the suggestions system. Some proposals lacking in any effort or creativity, whose only aim is to allow the worker to participate in the end-of-year raffle, have also been detected.

\section{PILOT EXPERIMENT WITH IMPROVEMENT TEAMS}

In mid-2004 two improvement teams were created. The subjects on which they were to work were: improving the quality of the product, reducing the percentage of wastage, 
saving time in changes of item and in cleaning, saving machine cycle time, standardisation of operations, increasing productivity or ergonomics.

These teams were formed by coordinators of small groups of workers, i.e. skilled workers. The team members received 20 hours of specific training in the characteristics of improvement groups and their objectives, and the tools for continuous improvement.

Each of the two groups consisted of five people from different areas of the firm (reception of goods, de-moulding, packing, slicing, cooked products, installations, maintenance...). This enabled them to share complementary knowledge and points of view, understand better the work carried out in other sections, and learn from the experiences of the rest.

The meetings were also attended by the firm's General Manager, to the extent that his schedule permitted, and by the continuous improvement leader, who acted as coordinator of the meetings (convening and moderating the meetings, making written note of agreements...). The continuous improvement leader participated in the analysis of the viability of the proposals and, together with the firm's managers, selected which ones would be implemented. The meetings took place every two weeks, within working hours, and normally lasted 30 minutes.

At the initial meeting a calendar and timetable for meetings was established. The next meetings were dedicated to completing the steps necessary for filling in the proposals: identification of the areas that needed improvements; analysis of the processes; generation of different alternative solutions; analysis of the costs, advantages and disadvantages of the alternatives (as far as possible each of these aspects was quantified to help in decision making); documenting how the improvements could be put into practice; consulting on their viability with the managers of the sections or departments involved, and summarising all this information on a proposal form. 
If the proposal was accepted by the management, it was implemented and monitored for a prudent period to see whether it was as effective as hoped, acting in consequence. At the end of the year, both teams made a presentation of the advances achieved, at a meeting attended by the managers of the firm and a delegation from the board of directors.

\section{Rewards for participation in the improvement teams.}

Part of the annual savings from each suggestion implemented are devoted to rewarding the members of the improvement team that proposed it. Proposals that generate savings of less than $6,000 € /$ year receive a "gift from the firm" (to be determined on each occasion). If the proposal saves between 6,000 and 15,000 €/year, $3 \%$ of the amount is awarded to the group as a prize. If the savings exceed 15,000 $€ /$ year the reward is $6 \%$ (with a limit of 6,000 euros).

\section{Results}

Each group convened 9 meetings, with an overall attendance of $80 \%$ of members. 28 proposals were presented, of which 23 were implemented. Following a trial period, it was confirmed that the proposals implemented would bring a saving of more than 105,000 €/year (Table III). In addition to this some proposals were generated that required heavy investment and were postponed for lack of resources, so they have not been included as proposals implemented. One proposal alone generated savings of more than $15,000 € /$ year, and 17 of the ideas implemented generated savings of less than $6,000 € /$ year each (altogether $39 \%$ of the savings). The total amount awarded in prizes, not counting "gifts from the firm", was $2,500 €(2,3 \%$ of the savings).

(Please insert table III about here) 
Despite the satisfaction with the teams' results, in these months of the pilot experiment some deficiencies have been observed in the system. For example, there are differences between the gratifications awarded for the suggestions system and for the improvement teams. The members of the teams find it hard to understand that the maintenance of the improvement teams program obliges the firm to make investments that are not necessary for the suggestions system. The teams program therefore attempts to incentivise the generation of highly profitable proposals (saving over 15,000 $€ /$ year), to the detriment of modest savings (less than $6,000 € /$ year). This problem is similar to the one commented on by Schuring and Luijten (2001). In addition, the fact that the prize for proposals saving less than 6,000€/year was not established, generated some problems.

Problems also arose with the payment of the rewards. These are paid at the end of the pilot experiment, not like those of the suggestions scheme which are paid once the idea has been approved. The reward for the effort is thus collected 8 months after having begun to propose and implement ideas, and loses a large part of its motivating capacity.

Most of the problems and opportunities for improvement put forward at the beginning of the pilot experiment were identified by the managers of the firm. The members of the group have not yet fully acquired the capacity to detect the problems or opportunities independently.

The general manager attended the first meetings and the workers perceived the interest of the top management. This produced motivation. However, as time passed, the managers cease to attend and the workers, observing this, come to think that what they say is of no importance and will not be taken into account, with the consequent de-motivation.

However, the presence of the general manager at meetings has not always been positive. At the meetings where he was present, "conservative" behaviour was 
observed on the part of the workers, with less flow of innovative ideas. Nevertheless, this problem decreased in importance as the workers became accustomed to the manager's presence.

A lack of communication and coordination between departments also appeared, especially with the department of Research and Development (R\&D). In some cases tests of products were duplicated, wasting time and effort, and information that could have been very useful both for the improvement teams and for R\&D was not used.

Furthermore, as not much information was made available about the launching of the pilot experiment, some middle managers or supervisors came to think that their functions were being interfered with. Also they considered that any extra activity relating to these teams, for example seeking information in the files, testing a product or collaborating in the implementation of a proposal, was a hindrance to carrying out their "real" work.

Another problem was that in some departments the authority of the continuous improvement leader was not recognised or his work was considered to be transitory, despite being backed by the firm's general management, to whom he was directly responsible. This caused delays in handing over information available in the archives, which had to be obtained through other channels.

Lastly, too much was attempted to start with. Ideas accumulated without proposals being formalised, especially the simplest ideas which would have produced small savings without financial gratification. The teams felt that no progress was being made and the ideas were not being executed, generating de-motivation. 


\section{DISCUSSION}

First, to deal with the first of our research questions, we have been able to verify that the suggestions program went through the stages proposed by the scientific literature: after a shaky start, an acceptable participation was achieved in terms of number of proposals presented (a number of which were put into practice) with levels similar to those shown by Frese et al ( 1999) and Schuring and Luijten ( 2001) and rather lower than those of Rapp and Eklund ( 2002). In the second year of its existence the "honeymoon effect" appeared (Lawler III 1991), but instead of the program disappearing, it entered into a re-launch phase (Rapp \& Eklund 2002) which has to be encouraged each year: by speeches from managers; by making the economic valuation of the proposals known to workers; by creating new systems like improvement teams and, probably, extending training in tools of continuous improvement (Bacdayan 2001;Greenbaum et al. 1988;Rapp \& Eklund 2002;Sillince et al. 1996;Terziovski \& Sohal 2000;Wood 2003). In this sense, the extrapolated data of 2005 seem to indicate an approaching danger of a fresh stagnation for lack of proposals (Bodek 2002;Lloyd 1999;Schuring \& Luijten 2001). Although the ones presented are very good, nearly all are implemented and they achieve savings similar to the previous year.

Secondly we want to make a comparative analysis of the two systems during the period of coexistence. The figures can be misleading: the number of proposals from the improvement teams, the degree of acceptance and the savings generated are strikingly higher than the results of the suggestions systems, particularly considering that only 10 workers have participated in the improvement teams and they have been functioning for only 6 months.

However, we must take into account some factors that differentiate between the two implementations. On the one hand, the maintenance of the suggestions system costs 
the firm hardly anything, except for a few hours of the managers of the departments evaluating the proposals. However, the maintenance of the improvement teams incurs overheads: the continuous improvement leader's salary, the proportion of managers' and workers' remuneration corresponding to the hours devoted to meetings, and training expenses (Griffin 1988).

Also, the excellent results of the improvement teams were achieved thanks to the participation and guidance of the managers and technicians who collaborated in the identification of proposals or the generation of alternatives. And, if that were not sufficient, the improvement teams were formed from the workers who had received the highest performance scores the previous year and who acted as coordinators of their co-workers, i.e. the workers who were best prepared and had most experience.

This is not to detract from the merit of the results achieved by the teams, but to highlight that extending the improvement teams program to more workers would not generate results proportional to the current ones: the costs of maintenance would rocket, the managers would not be able to be involved as they have been in the pilot experiment, the workers would not be so capable or motivated as the 10 selected for the pilot experiment, the program would no longer be a novelty (honeymoon effect) and at some point they would run out of problems to solve.

Altogether, though it is true that the improvement teams give better results than the individual suggestions systems (Rapp \& Eklund 2002), it is probably not recommendable to start directly with improvement teams, but for this to be the natural evolution to keep alive a system of continuous improvement that starts with suggestions systems (less costly to maintain and easier to implement) (Lawler III 1991).

In Table IV we summarise the principal differences in the functioning of the two programs. We highlight the fact that the improvement teams made a summary presentation of the achievements of the pilot experiment to the management of the firm 
and interacted with managers in the fortnightly meetings. Forming part of the improvement teams, therefore, as well as the personal satisfaction of recognition by the firm's top management and the other employees, could serve as a platform for workers' promotion. This increased the internal motivation for participating and doing it well, which is one of the main requisites for the success of the system (Choi et al. 1997;Fairbank \& Williams 2001;Greenbaum et al. 1988;Sillince et al. 1996).

The system of rewards in the teams was a cause of problems. On the one hand they are harder to obtain as the reward does not depend on the estimated savings, but on the verification of the savings following a trial period. Also the percentages awarded for proposals with small savings (the most numerous) are less than in the suggestions system, and finally, it takes quite a long time to reap the financial reward. These problems are similar to those commented on by Kerrin and Oliver ( 2002).

Another difficulty was that, although mention was made of the improvement teams in the quarterly internal news bulletin, the workers and middle managers of the factory were not aware of the creation of the teams nor of their attributions. Nevertheless, as the months passed, the information was disseminated, either by word of mouth among their co-workers or by the continuous improvement leader.

(Please insert table IV about here)

Finally, comparing the actual application (Table IV) with the theoretical recommendations (Table I), we can see that most of the recommendations made by the scientific publications have been adopted by the firm, except for the problems commented on above regarding the delay in evaluating the proposals in the suggestions system and the rewards and the publicity of the system in the improvement teams. 
These factors of success have been incorporated gradually. Some of them were present in the initial scheme of the suggestions system. Others have been added to mitigate the dysfunctions of the system, and others will form part of the proposed new system that it is intended to implement after the pilot experiment with improvement teams.

Thus, for example, a pre-campaign will be presented to announce the creation of the improvement teams and the procedure for joining them. In the new system, the workers will be able to choose between two parallel paths: to participate in a simple program in which they make a suggestion and are free of any further obligations (suggestions system), or to participate in a more complex program, in groups, where after making the suggestion, they have the possibility of using various resources offered by the firm and participating in the implementation of the ideas (improvement teams). These teams may be formed by free association or proposed by the management.

The rewards will be a percentage of the saving achieved in the first year after the implementation of the idea. This percentage will be set by the general management of the firm. Symbolic prizes will also be offered for ideas that generate small savings in order to keep up the motivation.

\section{LIMITATIONS AND FUTURE RESEARCH}

First of all, the conclusions of this study cannot be extrapolated beyond the particular context studied: a medium sized Spanish family firm with mass manufacture systems, belonging to a traditional sector.

Another limitation has been the lack of historical data on the savings provided by the suggestions system before our intervention. As remarked by Greenbaum et al. ( 1988) 
and Drach ( 1994) it is not usual to find in firms the degree of discipline and systematisation needed for gathering and keeping these data.

Finally, we lack perspective to value the evolution of the two systems in the future and the preferences of the workers. We would like to continue the research in order to find out whether one of the systems will prevail over the other and whether the system of improvement teams can survive its honeymoon phase and continue with positive results if the proposal is extended throughout the firm.

\section{CONCLUSIONS}

In the course of our investigation we have seen that there is no magic formula for the correct operation of the system of continuous improvement, but that the existing system has to be continually improved, correcting faults and trying always to contribute something new to re-launch the system every so often. In this sense, our data show a real experience of how a scheme of continuous improvement has been gradually transformed, from a very unsuccessful start, passing through different phases and finally delivering results for the firm.

This study has also permitted us to highlight the importance of continuous improvement in the firm from both the economic point of view and that of worker development. We have been able to observe the important role played by the workers in this type of programs and how gradual progress can be made in making all the firm's personnel (managers and workers) aware of the need for continuous improvement as an essential tool of competitiveness, i.e. to inculcate, in some way, the entrepreneurial culture necessary to carry it out, help it flow and encourage the correct functioning of suggestion systems and improvement teams. 


\section{BIBLIOGRAPHICAL REFERENCES}

Albors, J. \& Hervás, J. L. 2006, "Cl practice in Spain: its role as a strategic tool for the firm. Empirical evidence from the CINet survey analysis", International Journal of Technology Management, vol. 35, no. 5, pp. 380-396.

Bacdayan, P. 2001, "Quality improvement teams that stall due to poor project selection: an exploration of contributing factors", Total Quality Management, vol. 12, no. 5, pp. 589-598.

Bañegil, T. 1993, El sistema JIT y la flexibilidad de la producción Pirámide, Madrid.

Barrick, M. \& Alexander, R. 1987, "A review of quality circle efficacy and the existence of positive-findings bias", Personnel Psychology, vol. 40, pp. 579-592.

Bodek, N. 2002, "Quick and Easy Kaizen", IIE Solutions, vol. 34, no. 7, pp. 43-45.

Bond, T. C. 1999, "The role of performance measurement in continuous improvement", International Journal of Operations \& Production Management, vol. 19, no. 12, p. 1318.

Buch, K. \& Spangler, R. 1990, "The effects of quality circles on performance and promotions", Human relations, vol. 43, no. 6, pp. 573-582.

Choi, T. Y., Rungtusanatham, M., \& Kim, J. s. 1997, "Continuous improvement on the shop floor: lessons from small to midsize firms", Business Horizons, vol. 40, no. 6, pp. 45-50.

de Lange-Ros, E. \& Boer, H. 2001, "Theory and practice of continuous improvement in shopfloor teams", International Journal of Technology Management, vol. 22, no. 4, pp. 344-358.

Drach, B. 1994, "Use manufacturing standards to drive continuous cost improvement", Production and Inventory Management Journal, vol. 35, no. 1, pp. 20-25.

Fabi, B. \& Pons, O. 1995, "Los circulos de calidad una experiencia internacional", Alta Dirección no. 192 , pp. $275-285$.

Fairbank, J. F. \& Williams, S. D. 2001, "Motivating Creativity and Enhancing Innovation through Employee Suggestion System Technology", Creativity \& Innovation Management, vol. 10, no. 2, p. 68.

Frese, M., Teng, E., \& Wijnen, C. J. D. 1999, "Helping to improve suggestion systems: Predictors of making suggestions in companies", Journal of Organizational Behavior, vol. 20, no. 7, p. 1139.

García Lorenzo, A. \& Prado Prado, J. C. 2001, "Los sistemas de participación del personal en España.Diferencias en función del tamaño,certificación ISO 9000 y sector de actividad de las compañías", Alta Dirección no. 220, pp. 81-94.

Garcia-Lorenzo, A. \& Prado, J. C. 2003, "Employee participation systems in Spain. Past, present and future", Total Quality Management \& Business Excellence, vol. 14, no. 1, pp. 1524.

Greenbaum, H., Kaplan, I., \& Metlay, W. 1988, "Evaluation of problem solving groups: the case of cuality circles programs", Group \& Organization Studies, vol. 13, no. 2, pp. 133-147.

Griffin, R. 1988, "Consequences of quality circles in an industrial setting: a longitudinal assessment", Academy of management Journal, vol. 31, no. 2, pp. 336-358.

Grütter, A. W., Field, J. M., \& Faull, N. H. B. 2002, "Work team performance over time: three case studies of South African manufacturers", Journal of Operations Management, vol. 20, no. 5, pp. 641-657.

Jackson, T. \& Dyer, C. 1998, Diagnóstico corporativo: una herramienta para alcanzar la excelencia, 1 edn, TGP Hoshin (PRODUCTIVITY PRESS), Madrid.

Kerrin, M. \& Oliver, N. 2002, "Collective and individual improvement activities: the role of reward systems", Personnel Review, vol. 31, no. 3, pp. 320-337.

Lawler III, E. E. 1991, High involvement Management Jossey-Bass, San Francisco.

Lawler III, E. E., Mohrman, S., \& Benson, G. 2001, Organizing for high performance: employee involvement, TQM, reengineering, and knowledge management in the fortune 1000. The CEO report Jossey-Bass, San Francisco.

Li-Ping, T., Tollison, P., \& Whiteside, H. 1988, "Managers' attendance and the effectiveness of small work groups: the case of quality circles", The journal of Social Psychology, vol. 13, no. 3, pp. 335-344.

Lloyd, G. C. 1999, "'Stuff the suggestions box."', Total Quality Management, vol. 10, no. 6, p. 869.

Modarress, B., Ansari, A., \& Lockwood, D. L. 2005, "Kaizen costing for lean manufacturing: a case study", International Journal of Production Research, vol. 43, no. 9, pp. 1751-1760.

Nair, A. 2006, "Meta-analysis of the relationship between quality management practices and firm performance--implications for quality management theory development", Journal of Operations Management, vol. In Press, Corrected Proof. 
Prado Prado, J. C. 1998, "The implementation of continuous improvement through the participation of personnel: A case study", Production and Inventory Management Journal, vol. 39 , no. 2, p. 11.

Prado, J. C. 2001, "Beyond quality circles and improvement teams", Total Quality Management, vol. 12, no. 6, pp. 789-798.

Rapp, C. \& Eklund, J. 2002, "Sustainable development of improvement activities: The long-term operation of a suggestion scheme in a Swedish company", Total Quality Management, vol. 13, no. 7, pp. 945-969.

Sanchez, J. I., Kraus, E., White, S., \& Williams, M. 1999, "Adopting high-involvement human resource practices", Group \& Organization Management, vol. 24, no. 4, p. 461.

Schonberger, R. J. 1996, World Class Manufacturing: the next decade Free Press, New York.

Schroeder, R. G., Bates, K. A., \& Junttila, M. A. 2002, "A resource-based view of manufacturing strategy and the relationship to manufacturing performance", Strategic Management Journal, vol. 23, no. 2, p. 105.

Schuring, R. W. \& Luijten, H. 2001, "Reinventing suggestion systems for continuous improvement", International Journal of Technology Management, vol. 22, no. 4, pp. 359-372.

Sillince, J. A. A., Sykes, G. M. H., \& Singh, D. P. 1996, "Implementation, problems, success and longevity of quality circle programmes: A study of 95 UK organizations", International Journal of Operations and Production Management, vol. 16, no. 4, pp. 88-111.

Stohl, C. 1987, "Bridging the parallel organization: a study of quality circles effectivness," in Communication yearbook, vol. $10 \mathrm{H}$. Mc Laughlin, ed., Sage, California, pp. 416-430.

Stohl, C. \& Coombs, W. T. 1988, "Cooperation or Cooptation: An Analysis of Quality Circle Training Manuals", Management Comunication Quarterly, vol. 2, no. 1, pp. 63-89.

Tapping, D., Luyster, T., \& Shuker, T. 2002, Value Stream management eight steps to planning, mapping, and sustaining lean improvements, 1 edn, Productivity Press, New York.

Terziovski, M. \& Sohal, A. S. 2000, "The adoption of continuous improvement and innovation strategies in Australian manufacturing firms", Technovation, vol. 20, no. 10, pp. 539-550.

van Dijk, C. \& van den Ende, J. 2002, "Suggestion systems: transferring employee creativity into practicable ideas", $R \& D$ Management, vol. 32, no. 5, pp. 387-395.

Wood, A. 2003, "Managing Employees' Ideas From Where do Ideas Come?", Journal for Quality \& Participation, vol. 26, no. 2, p. 22.

Yin, R. 1994, Case study research, 2nd ed. edn, Sage, Thousand Oaks. 
Table I.- Enablers of the success of the programs

Involvement of workers. Intrinsic motivation

Involvement of managers

Continuous improvement leader

Training for workers and managers who participate in the program

Duration of the program

Emphasise the interest in obtaining a number of simple ideas

Make known the proposals accepted

Evaluate proposals rapidly and report to authors

Implement accepted proposals rapidly

The person who makes the proposal should participate in the implementation

Reward the accepted proposals financially (extrinsic motivation)

Start with pilot experiments before extending throughout the firm

Define clearly the objectives pursued by the program

Transparent system of selection of ideas; facilitate interaction with the evaluators

Simple and clear system for presenting suggestions

Use measurable indicators to identify the success of the proposals implemented

Formalisation of programs

Entrepreneurial culture to stimulate creativity 
Table II.- Result of the suggestions system

\begin{tabular}{|l|l|l|l|l|l|}
\hline & 2001 & 2002 & 2003 & $2004^{\star}$ & $2005^{\star *}$ \\
\hline $\mathrm{N}^{0}$ workers & 193 & 170 & 172 & 165 & 179 \\
\hline $\mathrm{N}^{\circ}$ proposals & 105 & 76 & 325 & 148 & 94 \\
\hline Proposals/worker/year & 0.54 & 0.45 & 1.89 & 0.90 & 0.52 \\
\hline$\%$ proposals implemented & $57 \%$ & $49 \%$ & $39 \%$ & $59 \%$ & $77 \%$ \\
\hline Savings (€/year) & n.a. & n.a. & n.a. & $51.200 €$ & $51.600 €$ \\
\hline
\end{tabular}

* During this year the suggestions system coexisted with the pilot experiment in improvement teams (the 10 workers participating in the pilot experiment have been subtracted from the number of workers)

** Extrapolating the available data (months from January to May).

$\star \star *$ Approximately $50 \%$ of the workers have a permanent contract. 
Table III.- Result of the improvement teams (6 months of year 2004)

\begin{tabular}{|l|l|l|l|l|}
\hline$N^{\circ}$ workers & $N^{\circ}$ proposals & Proposals/worker/year & $\begin{array}{l}\% \text { proposals } \\
\text { implemented }\end{array}$ & Savings (€/year) \\
\hline 10 & 28 & 2.8 & $82 \%$ & $106.581 €$ \\
\hline
\end{tabular}


Table IV-Comparison of the two systems

\begin{tabular}{|c|c|c|}
\hline Variable & Suggestions System & Improvement Teams \\
\hline Degree of formalisation & Consolidated. 5 years in operation. & Pilot Experiment. \\
\hline Participants & $\begin{array}{l}\text { All workers in the firm. Voluntary. } \\
\text { Individually or as group. }\end{array}$ & $\begin{array}{l}\text { "Voluntary" by invitation. Only two groups. } 10 \\
\text { participants. Selected employees. }\end{array}$ \\
\hline Training offered & None & 20 hours on group problem solving \\
\hline Awareness & Program well known & Hardly known by non-participants \\
\hline Rewards & $\begin{array}{l}\text { Financial. Proportional to the savings } \\
\text { generated. Paid after acceptance of the } \\
\text { proposal. Rewards for simple ideas that } \\
\text { are easy to implement. Symbolic } \\
\text { consolation prizes. }\end{array}$ & $\begin{array}{l}\text { Financial for savings over } 6,000 € \text {. Paid at the } \\
\text { end of the pilot experiment. Rewards ideas that } \\
\text { generate big savings. }\end{array}$ \\
\hline $\begin{array}{l}\text { Involvement } \\
\text { management }\end{array}$ & Not visible & $\begin{array}{l}\text { Continuous improvement leader. Attendance of } \\
\text { managers at meetings to help identify themes } \\
\text { and value proposals }\end{array}$ \\
\hline $\begin{array}{l}\text { Presentation } \\
\text { proposals }\end{array}$ & $\begin{array}{l}\text { Simple form. Presented in human } \\
\text { resources department }\end{array}$ & $\begin{array}{l}\text { Simple form (more complete than for } \\
\text { suggestions) filled in from data in the minutes of } \\
\text { meetings. The proposal is presented by the } \\
\text { continuous improvement leader to the } \\
\text { management of the firm }\end{array}$ \\
\hline $\begin{array}{l}\text { Economic valuation of } \\
\text { savings (quantification } \\
\text { of proposals) }\end{array}$ & $\begin{array}{l}\text { External committee. Managers of different } \\
\text { departments. No uniform criteria. Take a } \\
\text { long time to evaluate }\end{array}$ & $\begin{array}{l}\text { Coordinator of continuous improvement system . } \\
\text { Valuation of proposals in a short time (one or } \\
\text { two weeks). Public criteria. }\end{array}$ \\
\hline $\begin{array}{l}\text { Acceptance/rejection of } \\
\text { proposals }\end{array}$ & Management of the firm & Management of the firm \\
\hline Implementation of ideas & $\begin{array}{l}\text { Immediately after approval. The authors of } \\
\text { the proposal sometimes participate }\end{array}$ & $\begin{array}{l}\text { Immediately after approval. Team members } \\
\text { nearly always participate }\end{array}$ \\
\hline $\begin{array}{l}\text { Managers' impressions } \\
\text { of the success of the } \\
\text { program }\end{array}$ & $\begin{array}{l}\text { Satisfactory. Costs little or no money and } \\
\text { generates savings. It is necessary to } \\
\text { innovate the system to encourage } \\
\text { participation }\end{array}$ & $\begin{array}{l}\text { Very satisfactory. The savings are much greater } \\
\text { than the investment in maintaining the program. } \\
\text { Managers are thinking how to extend it and } \\
\text { make it compatible with the suggestions system. }\end{array}$ \\
\hline
\end{tabular}

